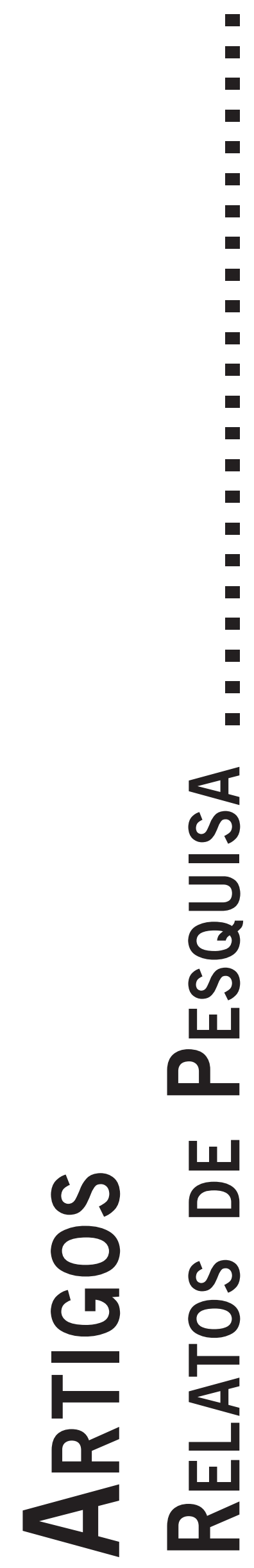




\title{
PERCEPÇÃO DE ADOLESCENTES COM CÂNCER: PESQUISA FENOMENOLÓGICA ${ }^{1}$
}

\author{
Pain Perception in Adolescents with Cancer: Phenomenological Research \\ Percepción del Dolor en Adolescentes con Cáncer: Investigación Fenomenológica
}

Hilze Benigno de Oliveira Moura Siqueira

Andressa Karina Amaral Plá Pelegrin

Rodrigo Ramon FALCONi GOMEZ

Talita de Cássia Raminelli da Silva

FÁtima Aparecida Emm Faleiros Sousa

\begin{abstract}
Resumo: A adolescência é um período da vida desafiador, principalmente, quando se vivencia uma doença como o câncer. Este estudo exploratório descritivo desenvolvido no Hospital de uma cidade do interior de São Paulo teve o objetivo de compreender como os adolescentes com câncer percebiam a vivência de dor. Para isso, a pesquisa foi desenvolvida no período de janeiro a dezembro de 2010 por meio de entrevistas fenomenológicas com 19 pré-adolescentes e adolescentes de ambos os sexos, com idade entre 10 e 19 anos, submetidos a tratamento de câncer. Os resultados mostraram a percepção da dor associada à vivência de situações existenciais significativas, os quais podem ser descritos nos temas seguintes: (1) percebendo a dor em conexão com os fatores emocionais; (2) apegando-se à memória dolorosa de hospitalização; (3) coexistindo com a dor; (4) percebendo a dor negativamente. Os adolescentes com câncer compreenderam sua experiência de dor em múltiplas dimensões. Diante disso, sugere-se que psicólogos, enfermeiros e médicos atentem à história de vida, ao tempo de hospitalização e a expressão dolorosa nessa fase da vida, para que, a partir dos relatos, os profissionais de saúde possam pensar em tratamentos e manejos que possam aliviar suas dores.
\end{abstract}

Palavras-chave: Dor; Neoplasias; Adolescente; Fenomenologia.

Abstract: Adolescence is a challenging period of life, especially when it experiences a disease like cancer. This exploratory descriptive study developed at the Hospital for an inner city of São Paulo aimed to understand how adolescents with cancer perceived the pain experience. For this, the research was carried out from January to December 2010 by means of phenomenological interviews with 19 pre-adolescents and adolescents of both sexes, aged between 10 and 19 years, who underwent cancer treatment. The results showed the perception associated with significant experience of existential pain situations, as the following topics: (1) realizing the pain in connection with emotional factors; (2) clinging to painful memory of hospitalization; (3) coexisting with pain; (4) realizing the pain negatively. The adolescents with cancer understood their painful experience in multiple dimensions. Thus, is suggested that psychologists, nurses and physicians pay attention the history of life, the duration of hospitalization and the pain expression this stage of life, so that, based on the reports, health professionals may think about treatments and management strategies that can relieve your pain.

Keywords: Pain; Neoplasms; Adolescent; Phenomenology.

Resumen: Adolescencia es un período con desafíos, especialmente cuando se experimenta enfermedad como el cáncer. Este estudio exploratorio descriptivo se desarrolló en el Hospital de la ciudad del interior São Paulo con el fin de entender cómo los adolescentes con cáncer perciben la experiencia del dolor. Por consiguiente, fue realizada desde enero hasta diciembre 2010 mediante entrevistas fenomenológicas con 19 pre-adolescentes y adolescentes de ambos sexos, edades comprendidas entre 10 y 19 años en tratamiento oncológico. Los resultados mostraron la percepción asociada con situaciones de dolor existencial, que se pueden describir en los siguientes temas: (1) percibir el dolor en relación con factores emocionales; (2) unido a la memoria dolorosa de la hospitalización; (3) coexistiendo con el dolor; (4) percibir el dolor negativamente. Los adolescentes con cáncer comprenden su experiencia del dolor en múltiples dimensiones. Por lo tanto, se sugiere que los psicólogos, enfermeras y médicos violan la historia de la vida, la duración de la hospitalización y la expresión de dolor en esta etapa de la vida, de modo que, a partir de los informes, los profesionales de la salud pueden pensar en tratamientos y estrategias de gestión que puede aliviar su dolor.

Palabras clave: Dolor; Neoplasias; Adolescente; Fenomenología.

Esta pesquisa contou com o apoio da Fundação de Amparo à Pesquisa do Estado de São Paulo - FAPESP: concessão do financiamento do projeto (processo n 2010/52584-8 Bolsa no País - Regular - Doutorado Direto). 


\section{Introdução}

A adolescência é a fase da vida demarcada cronologicamente pelas idades de 10 a 19 anos, segundo o Ministério da Saúde (MS), em consonância com a Organização Mundial de Saúde (OMS). Este período da vida pode ser subdividido em duas etapas: a pré-adolescência (10 aos 14 anos) e a adolescência propriamente dita (15 aos 19 anos) (Brasil, 2008). Tal período torna-se desafiador frente aos dados do Instituto Nacional Câncer (INCA), que estimaram cerca de 11.530 casos novos para o ano de 2012, com exceção dos tumores de pele não melanoma (Brasil, 2012).

O câncer corresponde a um grupo de várias doenças caracterizado pela proliferação descontrolada de células anormais e que pode ocorrer em qualquer local do organismo. Diferentemente do câncer de adulto, o câncer infanto-juvenil geralmente afeta as células do sistema sanguíneo e os tecidos de sustentação, enquanto que as do adulto afetam a do epitélio, que recobre os diferentes órgãos (câncer de mama, câncer de pulmão). O surgimento do câncer no adulto também difere dos tumores na infância e adolescência, em relação à etiologia. A limitação de evidências científicas não permite observar claramente a etiologia e os fatores de risco associados com causas externas ou ambientais; naquele, porém que tais riscos podem claramente ser associados a, por exemplo, fumo e câncer de pulmão (Brasil, 2010, 2012).

Dados mostram que entre as idades de 10 a 14 anos há mais prevalência para o desenvolvimento de câncer infanto-juvenil, sendo a sua prevenção um desafio com ênfase atual no diagnóstico precoce e na orientação terapêutica de qualidade. Devido às características de rápida invasão e crescimento, os possíveis tipos de tratamento consistem em cirurgia, quimioterapia e radioterapia, além de combinações como aquelas que envolvem transplantes de medula óssea (Straub, 2005; Brasil, 2012).

A experiência de câncer na adolescência traz dificuldades referentes ao ajustamento à nova realidade frente ao cotidiano da doença e ao contexto do cuidado terapêutico hospitalar. Tal vivência confronta-se à descoberta do corpo, à construção da identidade, à busca por autonomia e liberdade. É nesse cenário que ocorre o diálogo tênue entre vida-morte, muitas vezes, afastando o adolescente do seu convívio habitual e desencadeando fragilidades, incertezas, conflitos e inseguranças nele, em sua família e nos profissionais de saúde (Valle \& Françoso, 1999; Menossi, Zorzo \& Lima, 2012).

Em meio às mudanças e incertezas capazes de envolver as esferas biopsicossociais da vida dos adolescentes com câncer, os avanços científicos e tecnológicos vêm trazendo esperanças de cura com um índice de 70\% por meio de diagnóstico precoce e tratamento adequado (Brasil, 2012). No entanto, isso não ameniza o problema das queixas ou experiências de dor, comuns no serviço de saúde.
A dor acompanha quem vivencia o câncer e é variada de acordo a natureza, o estágio da doença e os métodos terapêuticos usados. As estimativas indicam que a dor pode ter intensidade significativa já no estágio inicial, sendo experimentada até $15 \%$ dos pacientes oncológicos com diagnóstico precoce, a dor pode ainda aumentar de $60 \%$ a $90 \%$ nos pacientes com câncer avançado (Arantes, 2008). Antigamente acreditava-se que os processos terapêuticos que curavam o câncer eliminariam a dor. Atualmente, reconhece-se que, mesmo depois de um manejo eficaz contra o câncer, muitos pacientes podem continuar a ter dor e, por isso, alguns estudiosos sugerem a utilização de métodos complementares e alternativos às terapias convencionais (Graner, Costa Junior \& Rolim, 2010). Entenda-se por manejo da dor, a administração ou tratamento na experiência dolorosa do câncer.

É comum a possibilidade do surgimento de sintomas da dor em regiões diferentes do corpo, em fases distintas ou nos tipos mais prevalentes das neoplasias infantis, o que pode confundir com outras doenças e dificultar o diagnóstico precoce (Braga, Latorre \& Curado, 2002; Brasil, 2008). Segundo Saunders (1976, 1986), a dor não envolve apenas a dimensão física (referente aos sintomas da doença, ao tratamento em si, as debilidades e problemas deste ou a comorbidades), sendo definida como Dor Total, ela abrange o ser humano de modo integral, podendo ser emocional (configura-se como parte do processo álgico e não apenas como simples reação à dor, ele estar relacionado a isolamento, solidão, medo, temor, ansiedade, depressão), social (crises familiares, tensões, rupturas, problemas financeiros, profissionais e com filhos) e espiritual (sentimento de vazio, culpa, arrependimento, incapacidade de comunicar e de receber ajuda).

A pesquisa científica mostra modos distintos para mensurar e qualificar o fenômeno da dor pediátrica, quais sejam: 1) Avaliação da Informação da Criança (relatos, brinquedos e desenhos para qualificar as experiências dolorosas do paciente); 2) Avaliação Comportamental ("check-list" com indicadores de dor) e; 3) Avaliação da Intensidade de Dor (instrumentos unidimensionais Escala de Cores, Escala de Faces Claro, Escala de Faces de McGrath entre outras). O resultado mais relevante encontrado foi sobre o modelo de McGrath, o qual é uma escala que pode ser usada pela enfermagem, que auxilia na avaliação e no gerenciamento de dor na oncologia pediátrica e em outras situações álgicas (Torritesi \& Vendrúsculo, 1998).

Alguns autores brasileiros têm sido referência na área da dor e da dor pediátrica, trazendo grandes contribuições científicas nesta área. É o caso de Almeida, Costa Júnior, Doca e Turra (2010) que defendem a importância de se pensar a experiência de dor por meio das variáveis psicossociais. Linhares e Doca (2010) ao estudarem a temática da dor pediátrica, mencionam o fenômeno como 
experiência subjetiva, enfatizando os diversos modos como a dor pode ser mensurada, os quais incluem autorrelato, observação e sinais objetivos de alteração fisiológica e comportamental. Turra (2012) apresenta reflexões dialogadas sobre a dor e o doer, oferecendo um universo rico em novos conteúdos, em sintonia com a Neurociência contemporânea, e constitui uma fonte de informação coordenada que abrange temas de interesse mais amplo de compreensão da dor vinculada aos aspectos subjetivos e diferentes fatores, incluindo genéticos, psicológicos, comportamentais, contexto ambiental dentre outros.

Na área de investigação da avaliação e da mensuração de dor humana, ressalta-se a grande contribuição de Sousa, Pereira, Cardoso e Hortense (2010), que apontam a importância de conhecer e compreender a multidimensionalidade álgica para melhor manejo ou tratamento, levando-se em consideração o modo como se percebe e escuta aquele que vivencia a experiência dolorosa.

Nesse sentido, o cenário preocupante da doença pode agravar-se com a presença da dor antes e depois do diagnóstico, pelos procedimentos terapêuticos, pelo estágio avançado da doença (Caponero, 2008), ou ainda, por causas advindas de fatores existenciais. Frente a isso, nos últimos anos, observa-se avanço e crescimento na produção científica sobre o tema dor oncopediátrica, abordando literatura sistematizada com diversos contornos do fenômeno da dor (Menossi, Lima \& Corrêa, 2008; Vilhena \& Padilha, 2009). Apesar dos avanços, o tema ainda é insuficientemente pesquisado quando comparado às produções científicas em adultos (Noble, Clark, Meldrum, Have, Seymour, Winslow \& Paz, 2005). Além disso, a experiência de dor do adolescente, se não for compreendida, pode representar um problema de saúde pública capaz de desencadear mais prejuízos, tais como: físico (incapacidade funcional), socioeconômico (gastos com medicamentos, deslocamentos do doente e acompanhante para centros de especialidade) e emocional (depressão, isolamento, resistências para adesão ao tratamento, agressividade direcionada aos profissionais de saúde...). Tudo isso, possivelmente já justificaria a necessidade de mais investigações científicas referentes à dor do adolescente com câncer.

Diante do exposto, considera-se pertinente escutar como a dor é percebida para esta poder ser mais bem manejada (entenda-se manejo da dor por administração ou tratamento da experiência de dor no câncer). Para tanto, o objetivo deste estudo foi compreender como os adolescentes vivenciam a dor frente à experiência de câncer.

\section{0 caminho metodológico}

Trata-se de um estudo qualitativo, exploratório descritivo, fundamentado na abordagem fenomenológica. Tal abordagem possui uma característica descritiva com base nos fenômenos vividos. A leitura e a análise fenomenológica possuem várias perspectivas filosóficas, as quais podem apresentar diferenças metodológicas significativas e gerar desafios à pesquisa. A proposta de MerleauPonty, apesar de receber influência do pensamento de seu mestre Husserl, faz uma releitura deste e defende uma fenomenologia existencial, de compreensão mundana, com um pensamento eminentemente crítico, que busca a essência vinculada à existência ou à facticidade do mundo vivido (Moreira, 2004).

Ao recolocar a essência na existência, o filósofo traz uma fenomenologia compreensiva, a qual insere o ser humano em um mundo pré-dado, explorando temas existenciais como percepção, temporalidade, corpo e intersubjetividade (Merleau-Ponty, 1945/2011). Isso possibilita convidá-lo a emergir no mundo relacionado ao processo de adoecimento e seu manejo. Na Fenomenologia Existencial de Merleau-Ponty, a metodologia é traduzida pela tríade: descrição - redução - compreensão fenomenológica. Tal tríade aparece ora como inspiração teórica para análise dos dados, ora como inspiração técnica estrita para o procedimento das análises (De Castro \& Gomes, 2011).

Merleau-Ponty considera a presença ativa do ser no mundo compartilhada, dado à linguagem, ao movimento, ao gesto, à presença e à corporeidade, com capacidade de sentir, comunicar e criar (Merleau-Ponty, 1945/2011). Ao privilegiar todas as formas de expressão mostra que, por meio da perspectiva fenomenológica, a linguagem não pode fragmentar-se à soma de palavras e estruturas gramaticais descritas, mas também a buscar novos sentidos a partir do movimento paradoxal e criativo de retomá-la e deformá-la. Neste artigo, o método descritivo fenomenológico foi privilegiado não pela busca da essência de patologias, mas na tentativa de desvelar o significado e compreender a experiência por quem as vivencia, seus significados na relação com o mundo humano, a sua história e a sua cultura (Merleau-Ponty, 1945/2011).

Decorrente disso buscou-se essa compreensão do significado da experiência dolorosa em adolescentes (de ambos os sexos) com câncer a partir do desenvolvimento da pesquisa no ambulatório de oncopediatria de um Hospital universitário do interior de São Paulo, no período de janeiro a dezembro de 2010. Para selecionar os participantes, utilizou-se como critério de inclusão, ter idades entre 10 e 19 anos, ter diagnóstico e estar em tratamento de câncer, independentemente da fase e do tipo de neoplasia. Excluíram-se aqueles que não apresentavam condições físicas e de compreensão para executar as tarefas solicitadas. O número de participantes do estudo foi determinado pelo critério da saturação dos dados (Fontanella, Ricas \& Turato, 2008).

Em relação aos procedimentos utilizados, primeiramente, foi solicitada a autorização dos pais ou responsáveis legais dos participantes menores e, também, de cada adolescente, por meio da declaração e assinatura do 
Termo de Consentimento Livre e Esclarecido. Os dados foram obtidos mediante uma entrevista aberta, audiogravada, realizada em ambiente reservado da instituição, que não prejudicasse a entrada para o consultório médico. Vale mencionar que, a pesquisa teve duração média de 1h30m e que, os pais/responsáveis ficavam próximos, com orientação para não interferirem nas tarefas da pesquisa.

Após o consentimento dos pais, conversou-se com os participantes, informalmente, a fim de estabelecer o primeiro contato, em um lugar mais reservado do ambulatório pediátrico. Quando se percebia que o adolescente estava mais à vontade, convidava-o para participar do estudo, sendo fornecidas as explicações necessárias e, caso consentisse, dava-se continuidade à coleta com a entrevista, pautada na questão norteadora: "Gostaria que me contasse se você já sentiu algum tipo de dor e como você compreende essa dor". A partir desses questionamentos foram buscados cada significado descrito pelo mesmo, a fim de possibilitar a compreensão do fenômeno doloroso.

O material da entrevista áudio gravada foi transcrito na íntegra e literalmente, todos esses resultados foram analisados de acordo com o referencial fenomenológico, segundo o modelo de análise proposto por Martins e Bicudo (2011). Foram seguidos os seguintes passos: 1) descrição que consistiu na leitura completa do material com vistas a uma descrição da experiência dolorosa de adolescentes com câncer e a primeira aproximação à vivência dos participantes; 2) retomada da leitura das descrições de forma mais lenta e atenta, identificando as "unidades compreensivas de significado", as quais organizam as peculiaridades da experiência; 3) síntese das unidades de significado, que consistiu na construção das categorias de análise que levaram à leitura compreensiva do fenômeno.

Para tanto, foram seguidos todos os cuidados Éticos preconizados em pesquisa com seres humanos, sendo importante ressaltar que esta investigação teve aprovação do Comitê de Ética em Pesquisa do Hospital das Clínicas da Faculdade de Medicina da Universidade de São Paulo de Ribeirão Preto sob Processo de n ${ }^{0}$ 3926/2009 e que os nomes dos participantes foram identificados com codinomes referentes a pedras preciosas para garantir o anonimato dos mesmos.

\section{Resultados e reflexões do vivido}

A caracterização dos adolescentes pode ser observada na Tabela 1, referente à idade, ao sexo e ao nome (fictício), no qual foi renomeado para o de pedras preciosas a fim de salvaguardar a identidade e realçar a importância de cada participante nessa pesquisa.
Tabela 1: Dados de identificação dos adolescentes com câncer, distribuídos pelo nome, pela idade e pelo sexo

\begin{tabular}{|c|c|c|}
\hline Nome & Idade & Sexo \\
\hline Calcedônia & 13 & $\mathrm{~F}$ \\
\hline Citrino & 11 & M \\
\hline Peridoto & 10 & M \\
\hline Berilo Verde & 13 & M \\
\hline Cristal & 13 & $\mathrm{~F}$ \\
\hline Quartzo & 18 & M \\
\hline Pérola & 13 & $\mathrm{~F}$ \\
\hline Âmbar Negro & 11 & M \\
\hline Âmbar & 13 & M \\
\hline Ônix & 15 & M \\
\hline Armazonita & 17 & $\mathrm{~F}$ \\
\hline Alexandrita & 13 & $\mathrm{~F}$ \\
\hline Opala & 12 & $\mathrm{~F}$ \\
\hline Hermatita & 18 & $\mathrm{~F}$ \\
\hline Jaspe & 14 & M \\
\hline Jade & 10 & $\mathrm{~F}$ \\
\hline Madrepérola & 17 & $\mathrm{~F}$ \\
\hline Safira & 11 & $\mathrm{~F}$ \\
\hline Brilhante & 12 & $\mathrm{~F}$ \\
\hline
\end{tabular}

A amostra total foi constituída por 19 participantes, sendo 05 pré-adolescentes e 14 adolescentes com câncer, a maioria do sexo feminino, com idades médias próximas a 13 anos e meio $(M=13,36 ; D P=2,47)$. Ao conhecer o universo das experiências álgicas de adolescentes com câncer, percebeu-se a dor sendo associada a fatos vivenciais, apresentados nas quatro temáticas seguintes: 2.1) percebendo a dor em conexão com os conteúdos emocionais; 2.2) apegando-se à memória dolorosa da hospitalização; 2.3) coexistindo com a dor e; 2.4) Percebendo a dor negativamente.

\subsection{Percebendo a dor em conexão com os conteúdos emocionais}

Os sentimentos de tristeza e de solidão puderam ser relacionados à dor, como mostra a seguir: Minha dor é minha tristeza, é muito triste... eu acho que todos um dia já sentiram dor (Calcedônia, 13 anos, feminino). Observa-se o adolescente conseguindo perceber a dor como experiência universal. A partir disso, um paradoxo em sua expressão foi instaurado, o qual permite revelar, também, o conhecimento sobre a existência de aspectos individuais e subjetivos envolvidos nessa experiência.

É importante mencionar, a intensidade da dor sendo percebida, desvelando os componentes físicos (por exemplo, dor na perna) e emocionais (tristeza, angústia e ao desespero), confluentes ao fenômeno álgico. Eu sinto muita dor, dói muito [pausa], ela vem na perna (...) vem na angustia e me dá um desespero (Calcedônia, 13 anos, feminino). Desse modo, na expressão dos adolescentes, evidencia-se o relato de conteúdos existenciais relacionados à dor. Penso no nada [pausa], um lugar vazio (...), sem ninguém (...) um lugar de solidão (Citrino, 11 anos, masculino). 
A maior dor que eu senti [pausa] foi quando minha mãe e meu pai se separaram [pausa], mas eu senti dor de cabeça, de barriga, muita dor de barriga... Ah! Eu penso em sofrimento [pausa]. Tipo quando eu soube que eu estava com Leucemia (...) (Safira, 11anos, feminino).

Os fenômenos dolorosos puderam ser associados a conteúdos emocionais, seja quando a percebem associada à solidão, seja quando qualificam as dores físicas, mas sem deixar de expressar a sua dor maior vinculada à experiência da separação de seus pais.

A expressão de Safira pode desvelar que a dor fica, muitas vezes, alojada nos pensamentos, trazendo a percepção do conteúdo existencial de sofrimento, semelhante ao provocado no dia que foi informada do diagnóstico de sua doença. Sabendo que a fenomenologia, enquanto movimento filosófico, permite a "volta às coisas mesmas", a descrição de que os sinais álgicos podem também estar atrelados às questões existenciais, o que suscitava uma busca por compreender a pessoa a partir do que ela expressa no seu conviver com a dor (Sanches \& Boemer, 2002).

Estudiosos apontaram as contribuições do pensar de Merleau-Ponty ressaltando que o ser criança e adolescente é focalizado, bem como, a importância da linguagem e da percepção, como fenômenos necessários de serem considerados, principalmente no que se refere à reversibilidade da fala, das palavras e o seu significado além daquilo que se vê e daquilo que é visto (Souza, Erdmann, Leite \& Santos, 2005).

Compreende-se que, quando passamos a considerar o adolescente com câncer, sua expressividade e sua experiência vêm à tona toda uma condição submersa nas alternâncias entre a sua saúde e a doença, entre sua linguagem e percepção, além da dor e seu caráter multifacetado relacionado às vivências e a historicidade carregada de conteúdos emocionais do seu existir no mundo.

\subsection{Apegando-se à memória dolorosa da hospitalização}

A memória relacionada ao ambiente hospitalar foi percebida como relevante e presente nas lembranças dos adolescentes. Os relatos que se seguem trazem essa realidade da memória dolorosa do adolescente associada à hospitalização, especialmente, ao tempo de internação e aos procedimentos terapêuticos.

\subsubsection{Dor pelas lembranças da internação}

A pessoa hospitalizada, geralmente, tem os seus valores pessoais e existenciais adaptados ao cotidiano hospitalar, além de perdas da individualidade e da liberdade (Almeida, Rodrigues \& Simões, 2007). Segundo os relatos, lembrar do tempo de internação hospitalar evoca sofrimento, dor, ociosidade e paralisação, nos quais confirmam algumas perdas como a da liberdade. A dor? [pausa], é, vem na minha cabeça que vou ficar internado (...), todo esse tempo parado, sem fazer nada, parece que eu vou ficar aqui preso (Peridoto, 10 anos, masculino).

A memória, mais do que um simples objeto de permanência da história, pode ser definida como a guardiã de algo que 'efetivamente ocorreu no tempo'. Nessa continuidade temporal, a memória, fragmentada e pluralizada, entrelaça-se à história com o objetivo de melhorar a percepção entre passado, presente e futuro (Silva, 2002). A definição anterior de memória corrobora com os postulados merleau-pontyanos, que se entrelaçam à história e à percepção mundana. O recordar é visto como experiência perceptiva e não como anterior à percepção, assim, memória emerge da percepção. $\mathrm{O}$ ato de lembrar é em si criação da memória (Merleau-Ponty, 1945/2011).

A impossibilidade de estudar, do convívio familiar e dos amigos foram outros aspectos referidos e associados à dor física. Sinto dor na cabeça, é aqui atrás, olha! [aponta para o lado esquerdo da cabeça]. Senti dor por não poder estar estudando por causa da internação e por estar longe de casa, da família, de meus amigos, sabe! (Brilhante, 12 anos, feminino). Essas experiências traumáticas de dor revelam que os adolescentes percebem o fenômeno álgico, rememorando-o no presente ou evitando-o no futuro.

O que compreendo? Vou dizer o que vem a minha mente quando penso na dor? Penso em ficar no hospital [pausa] sem contato com ninguém [pausa]. Sabia que depois que eu melhorar dessa doença, eu não quero mais passar nem frente daqui?[referindo-se ao hospital] (Cristal, 13 anos, feminino).

Quando se faz necessária a hospitalização, os adolescentes podem compreender sua dor simbolizada pelas lembranças do brusco distanciamento social (Almeida, Rodrigues \& Simões, 2007), que gera traumas, conflitos e fuga da realidade. Para Merleau-Ponty, lembrar-se de coisas ou de momentos que marcaram é lembrar-se de si mesmo e da indissociável relação com o mundo. Não se contempla de forma neutra o que se apresenta ao alcance dos olhos e as simbolizações e as recordações em torno disso provocam sentimentos agradáveis ou desagradáveis (Merleau-Ponty, 1945/2011).

\subsubsection{Dor pelas lembranças dos procedimentos terapêuticos}

No câncer pediátrico, a dor pode ser evidenciada quando relacionada aos procedimentos terapêuticos e aos efeitos colaterais advindos da quimioterapia e da radioterapia (Sakiroglu, Wood \& Cunin-Roy, 2009). 
Eu penso quando eu estava aqui dentro [referindo-se ao hospital], lembro das quimioterapias (Quartzo, 18 anos, masculino).

Lembro-me do sofrimento por causa das minhas cirurgias, pois desde de 2005 venho sofrendo com essa doença, desde o diagnóstico. Já tive duas vezes a doença (Pérola, 13 anos, feminino).

Para Menezes, Passarelli, Drude, Santos e Valle (2007), apesar dos extraordinários avanços médicos obtidos atualmente relacionados ao processo de tratamento do câncer infanto-juvenil, ainda existem muitos obstáculos a serem ultrapassados para que esse período não represente uma fonte de tensão e de estresse, desencadeada possivelmente a partir da descoberta da doença e com a vivência estendida de um turbilhão de sentimentos, os quais não desaparecem de uma hora para outra. Esses sofrimentos envolvendo dores físicas e psicológicas foram desvelados nos relatos pelas queixas sem haver dissociação entre os sintomas e os sentimentos de raiva provocados pelas reações do processo de adoecimento e hospitalização.

Já sofri bastante, bastante mesmo. Ah! vou contar... já senti dor de cabeça e, principalmente, ânsia de vômito, é muito horrível tudo isso (Âmbar Negro, 11 anos, masculino).

Quando penso na dor, lembro [pausa], eu passando mal, vomitando aqui. Parecia que eu tinha na cabeça umas fumacinhas, era de raiva por eu estar no hospital. Isso é quando eu faço a quimio, sinto muita dor (Ambar, 13 anos, masculino).

Dessa forma, além da recordação da dor pela internação e pelos procedimentos terapêuticos invasivos como o diagnóstico, a quimioterapia e a cirurgia, há ainda a dor em relação aos efeitos colaterais de vômitos, que fazem com que os sujeitos rememorem as vivências e, às vezes, reportem seu sofrimento ao ambiente hospitalar apesar de já estarem em outra situação ou momento da vida.

Flores e Costa Junior (2008) apontam para a necessidade de uma compreensão biopsicossocial do fenômeno doloroso, destacando a importância de tratamentos mais eficientes e coerentes com uma proposta sistêmica e idiográfica, que reconheça a relevância de fatores comportamentais e sociais sobre o tal fenômeno e a expressão do sofrimento decorrente.

\subsection{Coexistindo com a dor}

Esta categoria demonstra que a dor pode ser percebida coexistindo na vida dos adolescentes com câncer, como algo tolerável e manejável, capaz de ser suportado. Alguns desses adolescentes demonstram compreender a complexidade perceptual que envolve a dor física e emocional, porém não compreendem as razões de sua dor e os efeitos provocados por ela. Ah! dor? Ela vem e passa, vem e passa! Dói, vem e passa! Tive a perna amputada há 16 dias, fazer o que? Tem que ser assim... isso é normal, vou viver minha vida e vamos em frente (Ônix, 15 anos, masculino).

No desvelar dos relatos, perder algum membro do corpo foi difícil, mas apesar disso, percebeu-se um movimento interno que fortaleceu o adolescente doente, ajudando-lhe a continuar rumo ao futuro. Alguns adolescentes com câncer ao longo do tempo passam a coexistir com o problema da dor.

Dor (não sei)... na perna direita. Acho que eu suporto, é isso (Berilo Verde, 13anos, masculino).

Eu penso assim: que a dor [pausa], ela dar, vem no lugar que machuca ou no sentimento que a gente sente, mas nem sempre sabemos por que ela vem. Mesmo sendo emocional ou, às vezes, no físico, ela passa, eu sinto falta e só depois me acostumo (Armazonita, 17 anos, feminino).

Quando a dor persiste por dias e semanas, a pessoa adapta-se a ela, mesmo sem o perceber, essa foi uma das análises feitas por Sanches e Boemer (2002) quando buscaram encontrar um caminho para compreensão da dor por meio de algumas ideias da fenomenologia. As estudiosas compreenderam também que, a esfera biológica da dor pode ser percebida como campo de possibilidades, de transformações na existência, pois os resultados revelaram que à medida que o corpo físico se encontra doente, a vida em suas várias dimensões fica afetada, fundamentalmente no que se refere ao mundo da autorrelação. No entanto, o fenômeno torna-se suportável ou intermitente, passa a ser uma faceta da existência do paciente ainda que não mude em intensidade.

Tal estudo corrobora com os resultados dos adolescentes desta pesquisa, os quais se mostraram tolerantes, identificando-se às múltiplas dimensões de sua dor. Apesar dessa visível adaptação, eles têm dúvidas e curiosidades como, por exemplo, o "por que ela vem" (a dor) podendo gerar ansiedade. Essas curiosidades e ansiedades poderiam ser minimizadas pelo modo de comunicar ou dar informações do médico sobre as possíveis causas álgicas nesse processo de tratamento.

A informação ou comunicação ao paciente pode ser dada de forma adequada e inadequada, ou ainda negada. Segundo Perosa e Ranzani (2008) é mais comum que, mesmo sabendo da importância de colocar o paciente a par de seus problemas, o médico geralmente resista em informar o diagnóstico de forma explicita, não respondendo às perguntas. Outras vezes, de forma implícita, recorre a termos técnicos que mais ocultam do que transmitem informações. Frequentemente, o desejo de manter o paciente na ignorância é fortalecido por familiares. 
De modo geral seja tolerando, seja manejando a dor, parece que os adolescentes são conscientes e possuem uma linguagem própria para comunicá-la. Isso entra em conformidade com as ideias de Merleau-Ponty que postulam ser possível a linguagem expressa por meio do silêncio, dos gestos, das palavras, sabendo que o sujeito é corpo, mundo, história e de certa forma estabelece com estes uma permuta (Merleau-Ponty, 1991/1960).

\subsection{Percebendo a dor negativamente}

Esta categoria revela uma compreensão da dor como fenômeno negativo. Inserida em um espaço-temporal da doença cancerígena, o adolescente vivencia movimentos na rotina diária, remetendo a privação e diminuição da qualidade de vida, contrárias à autonomia e à liberdade esperadas nessa fase. Nesse espaço da relação corpo-mundo, a existência pessoal toca uma existência fisiológica que representa o princípio de inserção no mundo (Furlan \& Bocchi, 2003).

A dor no meu corpo é uma coisa muito ruim (...), ela (a dor) não deixa eu fazer nada, tenho medo dela (Calcedônia, 13 anos).

Quando penso em dor? Deixe eu pensar direito [pausa]! Eu penso em mal-estar, é isso, a dor é como um mal-estar. Penso às vezes que não terei um futuro (Alexandrita, 13 anos, feminino).

Eu acho que é ruim, porque se tem uma festa, na escola, aí você não pode ir, você fica no sofá amoadinha, quietinha, é muito ruim sentir isso [referindo-se a dor] (...) (Opala, 12 anos, feminino).

É difícil [pausa], muito difícil quando a gente sente dor [pausa]. Ah! Vou lhe contar! Dor é tipo um incômodo [pausa], um incômodo que faz mal a gente e deixa a pessoa sem conseguir fazer nada, parece que não irei mais conseguir (Jaspe, 14 anos, masculino).

O adolescente percebe seu corpo dolorido e, este, traz luz aos seus medos, incômodos, incertezas e vulnerabilidades. Por outro lado, os relatos nem sempre trazem um desvelamento sobre o significado atribuído à dor. Não sei dizer o que eu acho da dor, apenas sei que é horrível e quando penso nela [pausa], aí sei que é muito ruim sentir dor (Hematita, 18 anos, feminino).

O reconhecimento e o significado atribuídos às coisas, por meio da sensação em um corpo, poderão clarear melhor, apenas com o processo de maturação do indivíduo (Merleau-Ponty, 1945/2011), e de percepção, principalmente, em situações específicas como o da vivência de dor crônica em adolescentes com câncer. A percepção dolorosa, mediada pela sensação do corpo, foi formalmente descrita como horrível, ruim, chata e como aquela que trouxe incômodo e provocou mal-estar para quem a vivencia.
A sensação, segundo a fenomenologia de MerleauPonty, é uma maneira pela qual a pessoa é afetada por algo e, também, é uma experiência de um estado de mim mesma. A sensação amplia o conceito de percepção relacionado à atitude corpórea advindas do polo mundano e não da linearidade causal de estímulo-resposta (MerleauPonty, 1942/2012; Vieira \& Mantovani, 2010).

(...) Penso na parte do corpo doendo [pausa] e penso também naquela sensação ruim que dá (Jade, 10 anos, feminino).

É muito ruim sentir isso [referindo-se a dor] (Opala, 12 anos, feminino).

Dor, para mim, é a que incomoda. Eu só acho que eu estou com dor quando incomoda muito [pausa], é muito chato sentir dor (...), eu não gosto dela [referindo-se à dor], e sabe por quê? Porque parece que ela vem, né? parece que vem mesmo... e quer ficar um tempo (Madrepérola, 17 anos, feminino).

Ah! Dor? Sabe o que eu penso dela? Dor é tipo um incômodo que faz mal para meu corpo e para mim (...) (Jaspe, 14 anos, masculino).

Na medida em que o adolescente percebe negativamente a própria dor, o modo de pensar e de perceber tende a acionar os conteúdos álgicos, capturando a sensação no corpo em um período de tempo. Tal apreensão perceptiva unifica esboços imanentes na consciência e, nessa circunstância, a percepção álgica nunca se apresenta como processo acabado, mas em permanente mudança. Os resultados acima descritos lançam luz à penumbra da vivência de adolescentes que estão inseridos no mundo, no corpo doente e com dor. Este modo de existência mediada pela experiência pode levá-los a fala falante, ou seja, ao ato de falar que inaugura uma significação, e ainda uma tomada de consciência de um momento de sua realidade (Merleau-Ponty, 1945/2011).

\section{Considerações finais}

Na tentativa de reproduzir o que Merleau-Ponty (2011/1945) define por fala falante, buscou-se aproximar as ideias deste filósofo a expressão do adolescente com câncer a fim de possibilitá-lo atribuir um sentido em coexistência com a sua dor. Nesta investigação, foi possível observar os adolescentes compreenderem a experiência dolorosa, ora fazendo uso da memória do vivido durante a hospitalização, ora percebendo-a imbricada aos aspectos emocionais e aos aspectos negativos que afetam seu corpo e seu mundo de estar com câncer. Desse modo, desvelou-se a existência de movimentos dinâmicos "paralisa-dores" ou, movimentos que impulsionam a adquirirem forças emocionais e motivacionais para lutar e seguir em frente. 
Observou-se ainda que, por meio das entrevistas, os participantes foram capazes de expressar 'qual' e 'como é, a sua vivência de dor na experiência de câncer (dor com dimensão física? emocional? social?...).

Nesse cenário, o significado geral atribuído pelo adolescente desdobrou-se em múltiplas dimensões da dor: físicas, emocionais e sociais, isso permite refletir que, a percepção álgica do adolescente com câncer não é sem sentido e, consequentemente, não deve ser subestimada ou desvalorizada em nenhum momento do processo da doença, pois se essa expressão dolorosa for considerada, permitirá influenciar a equipe de saúde no desenvolvimento de estratégias a fim de ter um cuidado maior com a avaliação da dor e suavizar, talvez, alguns dos sofrimentos gerados pelo câncer pediátrico. Esses dados contribuíram para refletir sobre a possibilidade da dor, nessa fase da vida, ser mais bem manejada quando há interesse do profissional de saúde em identificá-la por quem a vivencia.

Em outras palavras, se a dor do adolescente for relatada à dimensão emocional, com características, por exemplo, de solidão, vazio ou saudades de familiares, a equipe profissional poderia buscar alternativas de contatos por telefone, cartas ou, se possível, a visita daquele familiar ao adolescente. Tal estratégia seria usada para constatar os benefícios direcionados ao estado geral de saúde do adolescente, ou benefícios adjuvantes pelo efeito positivo e analgésico possivelmente provocado por essa atitude.

Em suma, nota-se que, a investigação pode ser relevante no campo da saúde, mas principalmente, como possibilidade de subsídio teórico-científico para ser influenciado na atuação de médicos, enfermeiros, psicólogos, fisioterapeutas e outros profissionais implicados no contexto da oncologia e da dor pediátrica. No entanto, para desvelar a percepção álgica, tal como ela se apresenta, é preciso considerar a linguagem, o corpo, a história, o tempo e o mundo, quase pueril, do adolescente com câncer, tendo como fundamentos principais o acolhimento, a escuta, o respeito e a compreensão.

\section{Referências}

Arantes, A. C. L. Q. (2008). Dor e câncer. Em V. A. Carvalho (Org.), Temas em Psico-Oncologia (p. 287-293). São Paulo. Summus.

Almeida, I. S., Rodrigues, B. M. R. D., \& Simões, S. M. F. (2007). Hospitalização do adolescente. Revista Sociedade Brasileira e Enfermagem Pediátrica, 7(1), 33-9.

Almeida, F. F., Costa Junior, A. L., Doca, F.N.P. \& Turra, V. (2010). Experiência de dor e variáveis psicossociais: $\mathrm{O}$ estado da arte no Brasil. Psicologia: Ciência e Profissão, 18 (2), 367-376.

Braga, P. E., Latorre, M. R. D. O., \& Curado, M. P. (2002) Câncer na infância: análise comparativa da incidência, mortalidade e sobrevida em Goiânia (Brasil) e outros países. Cad. Saúde Pública (Rio de Janeiro), 18(1), 33-44.
Brasil (2008). Saúde do Adolescente: competências e habilidades. Brasília: Editora do Ministério da Saúde. Disponível em: <http://portal.saude.gov.br/portal/arquivos/pdf/saude_adolescente.pdf $>$.

Brasil (2010). Câncer no Brasil: Dados dos Registros de Câncer de Base Populacional, 3. Rio de Janeiro: Ministério da Saúde. Instituto Nacional de Câncer. Recuperado em agosto de 2012. Disponível em: <http/ www.inca.gov.br/ regpop/2011>.

Brasil (2012). Estimativa 2012: incidência de câncer no Brasil. Rio de Janeiro: Ministério da Saúde. Instituto Nacional de Câncer. Disponível em: <http://www.inca.gov.br/ estimativa/2012/>.

Caponero R. (2008). O controle de dor associado às neoplasias ainda é insuficiente. Revista Dor e Analgesia (São Paulo), 1(3), 4-11.

De Castro, T. G., \& Gomes, W. B. (2011). Movimento fenomenológico: controvérsias e perspectivas na pesquisa. Psicologia: Teoria e Pesquisa, 27(2), 233-240.

Flores A. M. N., \& Costa Junior, Á. L. (2008). Modelo biopsicossocial e formulação comportamental: compreendendo a cefaléia do tipo tensional. Psicologia em Estudo, 13(1), 143-151.

Fontanella, B. J., Ricas, J., \& Turato, E. R. (2008). Saturation sampling in qualitative health research: theoretical contributions. Cadernos de Saúde Pública, 24(1), 17-27.

Furlan, R., \& Bocchi, J. C. (2003). O corpo como expressão e linguagem em Merleau-Ponty. Estudos de Psicologia, 8(3), 445-450.

Graner, K. G., Costa Junior, A. L., \& Rolim, G. S. (2010). Dor em oncologia intervenções complementares e alternativas ao tratamento medicamentoso. Temas em Psicologia, 18(2), 345-355.

Linhares, M. B. M., \& Doca, F. N. P. (2010). Dor em neonatos e crianças: avaliação e intervenções não farmacológicas. Temas em Psicologia, 18(2), 307-325.

Martins, J., \& Bicudo, M. A. V. (2011). A pesquisa qualitativa em Psicologia: fundamentos e recursos básicos. São Paulo: Centauro.

Menezes, C. N. B., Passareli, P. M., Drude, F. S., Santos, M. A., \& Valle, E. R. M. (2007). Câncer infantil: organização familiar e doença. Revista Mal Estar e Subjetividade, 7(1), 191-210.

Menossi, M. J., Lima, R. A. G., \& Corrêa, A. K. (2008). Pain and the challenge of interdisciplinarity in child care. Revista Latino-Americana de Enfermagem (Ribeirão Preto), 16, 489-499.

Menossi, M. J., Zorzo, J. C. C., \& Lima, R. A. G. (2012). The dialogic life-death in care delivery to adolescents with cancer. Revista Latino-Americana de Enfermagem, 20(1), 126-134.

Merleau-Ponty, M. (2011). Fenomenologia da percepção. São Paulo: Martins Fontes (Original publicado em 1945). 
Merleau-Ponty, M. (2012). A estrutura do comportamento. (M. V. M. Aguiar, Trad.). São Paulo: Martins Fontes. (Original publicado em 1942).

Merleau-Ponty M. (1991). A linguagem indireta e as vozes de silêncio. Em Signos (39-88). São Paulo: Martins Fontes (Original publicado em 1960).

Moreira, D. A. (2004). O Método Fenomenológico na Pesquisa. São Paulo: Pioneira Thomson Learnig.

Noble, B., Clark, D., Meldrum, M., Have, T. H., Seymour, J., Winslow, M., \& Paz, S. (2005). The Measurement of Pain, 1945-2000. Journal Pain Symptom Management, 29(1), 14-21.

Perosa, G. B., \& Ranzani, P. M. (2008). Capacitação do médico para comunicar más notícias à criança. Revista Brasileira de Educação Médica, 32(4), 468-73.

Sakiroglu, C. O., Wood, C., \& Cunin-Roy, C. (2009). Pain in adolescents with cancer. Bulletin du Cancer, 96(2), 37-45.

Sanches, L. M., \& Boemer, M. R. (2002). O convívio com a dor: um enfoque existencial. Revista Escola de Enfermagem (USP), 36(4), 386-393.

Saunders, C. (1976). Care of the dying-4. Control of pain in terminal cancer. Nursing Times (London), 72(22), 1133-35.

Saunders, C. (1986). The Nature and Nature of Pain Control. Journal of Pain and Symptom Management (editorial), 1(4), 199-201.

Silva, H. R. (2002). Rememoração, comemoração: as utilizações sociais da memória. Revista Brasileira de História (São Paulo), 22(44), 425-438.

Sousa, F. A. E. F., Pereira, L. V., Cardoso, R., \& Hortense, P. (2010). Multidimensional Pain Avaliation Scale, Revista Latino Americana de Enfermemagem, 18(1), 3-10.

Souza, A. I. J., Erdmann, A. L., Leite, J. L., \& Santos, E. A. K. (2005). Contribuições do Pensar de Maurice Merleau Ponty sobre o ser criança e o ser adolescente: subsídios para o fazer da enfermagem pediátrica. Revista Sociedade Brasileira de Enfermagem Pediátrica, 5(1), 39-45.

Straub, R. (2005). Psicologia da saúde. Porto Alegre: Artmed.

Torritesi, P. \& Vendrúsculo, D. M. S. (1998). A dor na criança com câncer: modelos de avaliação. Revista Latino Americana de Enfermagem de Ribeirão Preto, 6(4), 49-55.

Turra, V. (2012). Neurociências e Psicologia Analítica: sobre a Dor e o Doer. Em V. E. Antonio \& R. S. Batista. (Orgs.), Neurociências: diálogos e interseções (p. 631-645). Rio de Janeiro: Rubio.

Valle, E. R. M., \& Françoso, L. P. C. (1999). Psicooncologia pediátrica: Vivências de crianças com câncer. Ribeirão Preto: Scala.

Vieira, K. O., \& Mantovani, H. J. (2010). Merleau-Ponty: introdução à estrutura do comportamento. Revista Católica, 2(3), 93-100.

Vilhena, M., \& Padilha, R. (2009). Psychism, pain and adolescence: an interdisciplinary study. Adolescência e Saude, $6(2), 30-35$.
Hilze Benigno de Oliveira Moura Siqueira - Possui Doutorado em Ciências pela Escola de Enfermagem de Ribeirão Preto da Universidade de São Paulo (EERP/USP), Graduação em Psicologia e Especialização em Psicologia Clínica na Abordagem Fenomenológico-Existencial pela Universidade Federal do Rio Grande do Norte e é Pesquisadora do Grupo do Laboratório de Avaliação e Mensuração da Dor Humana da Escola de Enfermagem de Ribeirão Preto - USP. Av. dos Bandeirantes, 3900. Sala 141. Monte Alegre. CEP: 14.040-902. Ribeirão Preto (SP). E-mail:hilzes@yahoo.com

Andressa Karina Amaral Plá Pelegrin - Mestre em Ciências pela Escola de Enfermagem de Ribeirão Preto da Universidade de São Paulo (EERP/USP), Enfermeira do Hospital das Clínicas de Ribeirão Preto e Graduada em Enfermagem pelo Centro Universitário Barão de Mauá. E-mail: andressapelegrin@yahoo.com.br

Rodrigo Ramon Falconi Gomez - Graduando de Psicologia pela Universidade Paulista de Ribeirão Preto (UNIP) e aluno de Iniciação Científica pela Escola de Enfermagem de Ribeirão Preto da Universidade de São Paulo (EERP/USP).

E-mail:sonokeiba@yahoo.com.br

Talita de Cássia Raminelli da Silva - Doutoranda da Escola de Enfermagem de Ribeirão, Graduada em Psicologia pela Escola de Enfermagem de Ribeirão Preto.

E-mail: talita_girl@yahoo.com.br

Fatima Aparecida Emm Faleiros Sousa - Professora Titular da Escola de Enfermagem de Ribeirão Preto da Universidade de São Paulo (EERP/USP). Graduada em Enfermagem pela Escola de Enfermagem de Ribeirão Preto da Universidade de São Paulo, em Pedagogia pela Universidade Estadual Paulista e em Psicologia pela Universidade Paulista de Ribeirão Preto. Líder do Grupo do Laboratório de Avaliação e Mensuração da Dor Humana da EERP. Endereço Institucional: Av. dos Bandeirantes, 3900. Sala 141. Monte Alegre. CEP: 14.040-902. Ribeirão Preto (SP).

E-mail:ffaleiros@usp.br

Recebido em 14.04.2013 Primeira Decisão Editorial em 20.12.2013 Segunda Decisão Editorial em 04.11.2014 Aceito em 04.12.2014 